\title{
Compressive behaviour of dam concrete at higher strain rates
}

\author{
A. Caverzan ${ }^{\text {a }}$, M. Peroni, and G. Solomos
}

European Commission Joint Research Centre (JRC), Institute for the Protection and Security of the Citizen (IPSC), European Laboratory for Structural Assessment (ELSA), via E. Fermi 2749, Ispra (VA), 21027 Italy

Received 24 August 2015 / Received in final form 5 February 2016 Published online 18 March 2016

\begin{abstract}
The mechanical behaviour of concrete when subjected to impact or blast has still many aspects requiring further study. Dam concrete is characterized by large coarse aggregates, hence large specimen sizes are needed in order to study a representative volume of the material. Exploiting an innovative equipment, based on Hopkinson bar techniques, the dynamic behaviour of concrete of $64 \mathrm{~mm}$ maximum aggregate size has been investigated. Direct dynamic compression tests have been performed on medium and large size cylindrical samples. Full stress-strain curves have been obtained, which have allowed the estimation of fracturing energies and of the relevant dynamic increase factor. The experimental campaign has also included a reference standard concrete in order to highlight the peculiarity of the dam concrete at high strain rates and to validate the transition of this type of testing to very large specimens.
\end{abstract}

\section{Introduction}

In our modern societies an increasing number of structures and infrastructures are considered critical due to their socio-economic relevance. A structural collapse or decay in their functionality can have a tremendous impact in the daily life of million of people. Critical structures should be considered as a potential target of terrorist attacks and exceptional scenarios like blast or impacts must be taken into consideration. In order to build new and secure structures or to retrofit existing critical components, appropriate design methodologies and approaches must be given to designers. These tools have to incorporate proper materials models, based on the mechanical response of the materials to such severe loads, and should therefore include strain rate effects.

According to several published technical studies, and in particular referring to compression and tension tests, an enhancement of the concrete mechanical characteristics is observed as the strain-rate increases [1-6]. This refers to the strength, the ultimate strain, the elastic modulus and the fracture energy, for which however some studies report a different trend. A plausible physical explanation of this behaviour

\footnotetext{
a e-mail: alessio.caverzan@jrc.ec.europa.eu
} 
is that at higher strain-rates all particles of the material are accelerated under the action of the very fast growing loading pulse, resulting in a more uniform distribution of strain and strain energy. Consequently the influence of existing single defects and voids becomes less important, as the whole material volume works together to resist the applied load. Similarly, the theory of multi-activation of the fracture process at impact regime [7] or theories like limited crack propagation rate, pore water and multiple cracking [8-10] have also been proposed and provide explanations to the observed phenomena.

Despite the effort and experimental work carried out so far, the data available for concrete at impulsive loading are still relatively few, in addition to the fact that they are not always directly comparable between them. The reason for this could originate from the complexity of the relevant experiments, even for the simple compression and tension tests. Often the data have been obtained by different experimental techniques and in dynamic testing such differences can be more marked because of the wave propagation and inertia effects. For this reason it is essential that apparatuses capable of handling the wave propagation be used for the mechanical characterization of concrete at high strain-rates.

As widely recognized, the Split Hopkinson Pressure Bar (SHPB) is the more suitable technique for the determination of the mechanical properties of structural materials under high loading rates [11-17]. While standard Hopkinson bars with a diameter in the range of $10-20 \mathrm{~mm}$ are sufficient for dynamic testing of fine-grained materials, like steel, larger bars are needed to load concrete specimens of meaningful size. In fact, the specimen size for concrete should be larger than four times the maximum aggregate size (as a rule-of-thumb), in order for a representative volume of material to be tested [18]. The material and the dimension of the bar have also to satisfy the appropriate conditions in order for the one-dimensional theory of wave propagation to be applicable. The HOPLAB laboratory with the necessary modifications possesses such capacities, as described below, and is utilized to obtain reliable results.

The objective of this study is to investigate the dynamic compressive properties of dam concrete. Concerning this field, it is noted that the vast majority of the existing data has been derived from tests with normal concrete, i.e. with small aggregates and compressive strengths between $25 \mathrm{MPa}$ and $50 \mathrm{MPa}$ [19]. Very little is known about the dynamic behaviour of dam concrete, where the compressive strength is usually smaller and the maximum aggregate size can be substantially greater, up to $150 \mathrm{~mm}$, with peculiar other problems arising thereof. Dam concrete would require new supporting experimental evidence, which should at least provide data regarding its dynamic strength. However, more information about the material characteristics, such as the ultimate strain, the influence of the relative humidity and of the aggregate size, the fracture energy etc., would be desirable, since the modern constitutive laws for concrete tend to encompass more parameters, and consequently this imposes further demands on testing.

\section{Materials and specimens description}

In the framework of a join project [20], all specimens have been prepared by the Politecnico di Milano. Some considerations taken into account in the design of the mixtures are as follow. Concretes with relative small cement content have been produced. The huge volumes of dam structures, which suggest the use of large aggregates, have the added advantages of requiring less cement per unit volume and consequently of generating less heat in the exothermic cement-water reaction. The reason to limit the rate of development of heat of hydration is related to the tensile stresses which 
may develop in the cooling phase due to the temperature gradients. This requirement has suggested the use of lower quantities of cement per unit volume and of the type II Portland cement, characterized by a slower strength development. No pozzolanic materials have been used, and it has been thought preferable to avoid the use of air entraining admixtures. Chemical admixtures have been added only in order to make the concrete more workable, to control the time of setting and to increase the resistance to freezing $[21,22]$. The aggregate is limestone of alluvial origin.

Table 1. Mix design $(\mathrm{w} / \mathrm{c}=0.55)$.

\begin{tabular}{lcc}
\hline Constituent & $\begin{array}{c}\text { Dam concrete } \\
{\left[\mathrm{kg} / \mathrm{m}^{3}\right]}\end{array}$ & $\begin{array}{c}\text { Standard concrete } \\
{\left[\mathrm{kg} / \mathrm{m}^{3}\right]}\end{array}$ \\
\hline Portland cement Type II & 236 & 273 \\
Fine aggregate $(\mathrm{d}<4 \mathrm{~mm})$ & 479 & 651 \\
Coarse aggregate $0(4 \mathrm{~mm}<\mathrm{d}<6 \mathrm{~mm})$ & 125 & 237 \\
Coarse aggregate $1(6.3 \mathrm{~mm}<\mathrm{d}<12.5 \mathrm{~mm})$ & 271 & 256 \\
Coarse aggregate $1.5(10 \mathrm{~mm}<\mathrm{d}<20 \mathrm{~mm})$ & 208 & 296 \\
Coarse aggregate $3(16 \mathrm{~mm}<\mathrm{d}<32 \mathrm{~mm})$ & 229 & 532 \\
Large Coarse aggregate $(24 \mathrm{~mm}<\mathrm{d}<64 \mathrm{~mm})$ & 770 & - \\
Water & 130 & 150 \\
\hline
\end{tabular}

The final mix compositions, proposed by Politecnico di Milano, are presented in Table 1. They follow closely the Fuller curve and they satisfy also the requirement that they give rise to a compact mesostructure, which is essential in order to make the results comparable between the dam concrete and the standard concrete, fabricated with standard size aggregates (with maximum size of $32 \mathrm{~mm}$ ).

As seen, the rule that the size of the specimen should be greater than four times the maximum aggregate size is not strictly satisfied. There has been a compromise in this investigation between using the largest aggregates possible and at the same time not exceeding the capacities of the machine for the static tests. If for the large coarse aggregates an average size of $\sim 44 \mathrm{~mm}$ can be considered, it could be claimed that the above rule is satisfied in an average sense.

In order to compare the dynamic behaviour of dam and standard concrete several specimens were cast at the same time for each material. Dynamic compressive testing has been carried with cylindrical samples of diameter equal to $200 \mathrm{~mm}$, and length equal to $200 \mathrm{~mm}$ and $400 \mathrm{~mm}$. According to their length, they are marked for dam and standard concrete, correspondingly, as DAM200, DAM400 and STD200, STD400.

\section{Experimental procedures}

The experimental campaign for the study of the mechanical properties of dam concrete included both static and dynamic conditions. Static tests were conducted at the Politecnico di Milano labs and they are not the object of the present work. Only the principal material characteristics have been reported herein, i.e. the measured mean static compressive and tensile strength. However, it is important to highlight that materials, specimen sizes and geometry investigated in static and dynamic field are the same.

As introduced above the HOPLAB facility (of the Joint Research Centre at Ispra, Italy), with some innovative modifications has been efficiently utilized and proved reliable in obtaining valid results. The HOPLAB is one of the biggest existing Hopkinson bar apparatuses with a length of more than $200 \mathrm{~m}$ and a bar diameter of 
$72 \mathrm{~mm}$ made of high strength steel. Different from a classical split Hopkinson bar, where a projectile is used to generate the main impact loading pulse, a statically pre-stressed high strength steel cable which is the physical continuation of the input bar is used. Through pre-tensioning and suddenly releasing this cable, rectangular force pulses of up to $2 \mathrm{MN}, 250 \mu \mathrm{s}$ rise time and $40 \mathrm{~ms}$ duration can be generated and applied to the specimen tested. The cable pre-tensioning is effected by means of a hydraulic actuator electronically controlled and placed at one end, while the instantaneous release of its opposite end is achieved through breaking of a fragile bolt which sustained all the pretension load. The fracture in the bolt is induced by a small detonation of explosive inserted in it. The high strength steel cable is $100 \mathrm{~m}$ long and has an equivalent diameter of $72 \mathrm{~mm}$, too. The tensile pulse generated is transmitted to the actual input bar, to the specimen and to the output bar (which is about $90 \mathrm{~m}$ long). At the distal end of the output bar a hydraulic damper allows to dissipate the remaining energy emanating from the cable and transferred through the specimen to the output bar.

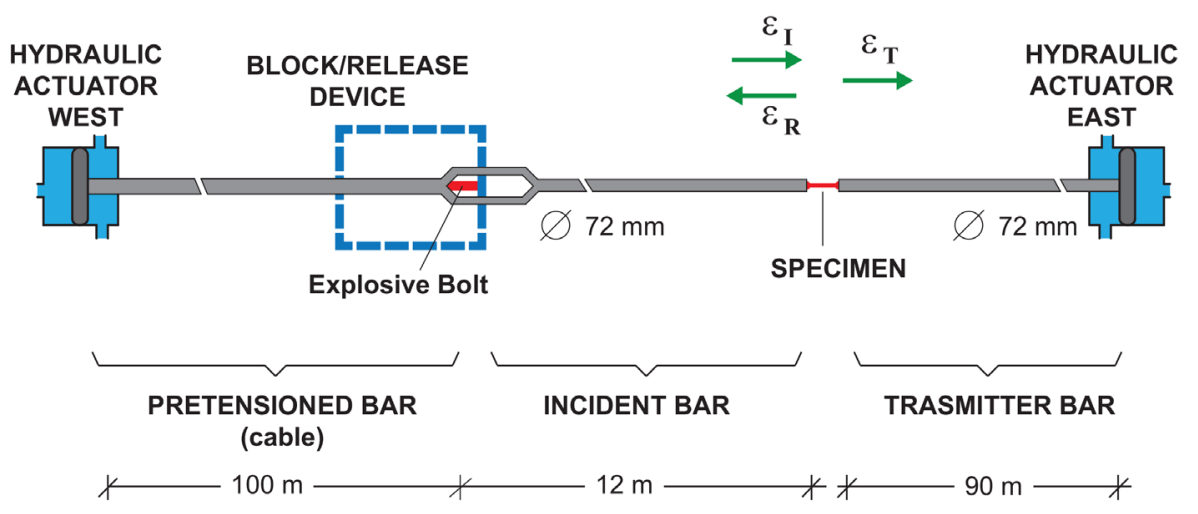

Fig. 1. Scheme of the "natural" HOPLAB configuration.

The configuration described above can be considered as the "natural" one (Fig. 1) and in this configuration HOPLAB can generate dynamic tensile pulses in a straightforward manner. By modifying the central part of the equipment it is possible to exploit the tensile wave generated in order to perform different types of tests, as for example compression. Of course, different aspects and parts of the equipment have to be re-designed, improved and checked, as reported in [23,24]. Without entering into details, a brief description of the modified facility is illustrated here. The basic element of the new configuration is the introduction of the twin incident and twin transmitter bars connected to high strength steel plates at their ends; between the plates a large specimen can be accommodated and compressed as represented in Fig. 2.

Thanks to this "motion inversion frame" the available tensile pulse can be transformed into a compressive one on the specimen, which is thus compressed and failed dynamically.

The twin bars are made of high-strength stainless steel and are $6 \mathrm{~m}$ long with a diameter of $60 \mathrm{~mm}$. The compressive load is applied to the sample by means of the two high-strength steel plates. Plates can transfer the compressive load but are also useful to keep aligned the four bars. Input and output twin bars are rigidly connected to their own plate and can slide in the two plastic bearings of the other plate (Fig. 2). Such a configuration leads to a very stiff mechanical structure and to a minimization of the oscillations during the test. The specimen ends are always treated with a friction reducing materials (stearic acid).

Nicolet Multipro transient recorders with a maximum sampling-rate of $1 \mathrm{MHz}$, synchronized with the electrical signal that triggers the explosion of the fragile bolt, 


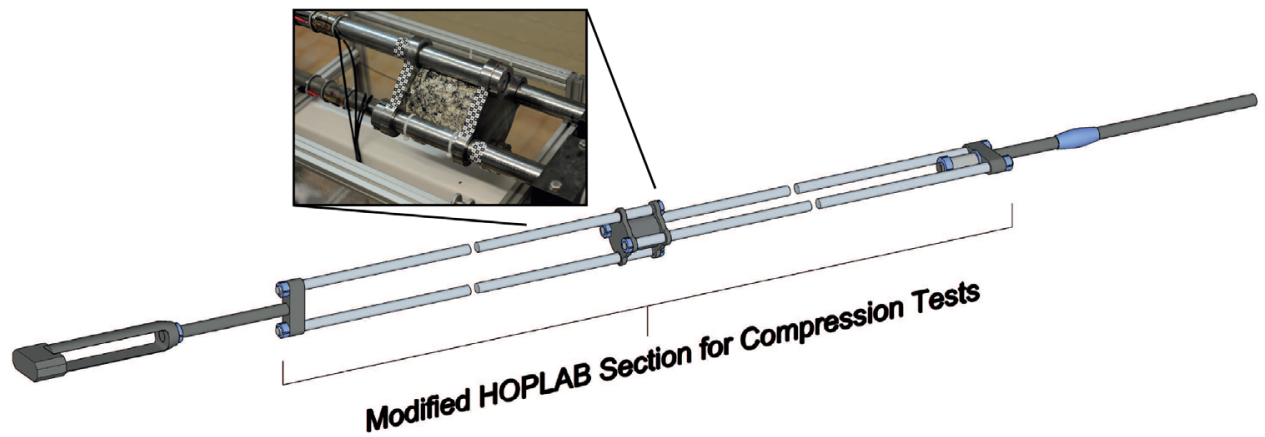

Fig. 2. Schematic of the new HOPLAB configuration and details of the plates mounted at the twin bars ends and the sample.

have been used. In addition a high-speed camera, which is synchronized with the transient signals, has been intensively used.

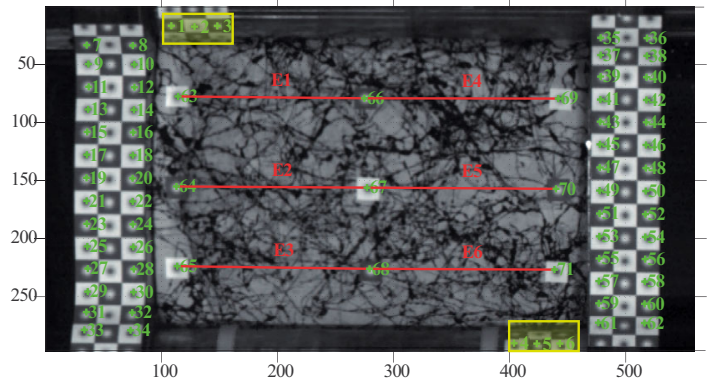

(a)

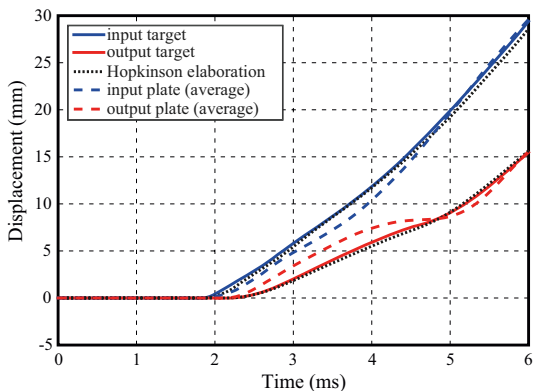

(b)

Fig. 3. Digital Image Correlation techniques: (a) Example of target distribution; (b) comparison of bar displacements computed with Hopkinson and DIC techniques.

The camera is an IDT-Y4 operate at $15000 \mathrm{fps}$ at maximum resolution. High speed photo sequences has allowed to obtain full-field displacement measurements by applying Digital Imagine Correlation (DIC). In Fig. 3 the different targets used to compute and compare Hopkinson bar analysis and DIC analysis are shown. The discrete black and white checker squares are highlighted with the green numbers in Fig. 3(a) and they have been used to calculate global and local information such as displacement and velocity of input and output plates or strain along generators on the cylindrical surface. Moreover, the targets highlighted with the yellow boxes and placed at the ends of the input and output twin bars were used to compute the displacements of the bars. Figure 3(b) presents the comparison of displacement at the end of the bars obtained with the DIC algorithms applied to high speed photo sequence (yellow targets) and the data obtained with the Hopkinson theory after the compensation of distortion due to dispersion phenomena $[25,26]$. The average displacements of the input and output plates (green targets) are also shown. They are clearly different from the end displacements of the corresponding bars, a fact taken into account when constructing the stress-strain diagrams below. Moreover, DIC has been used also for full-field measurements. In order to detect and compute the field measurements the sample surface was painted with a random black and white pattern which is needed in the post processing phase. By means of optical flow algorithms it has been possible to compute displacements and strains on the sample visible surface, and thus follow the early development of cracking. 


\section{Tests results and discussion}

Three tests per case have been performed. Tests results are shown in Fig. 4 in terms of diagrams of nominal stress versus axial strain for the specimens characterized by a length of $200 \mathrm{~mm}$ and $400 \mathrm{~mm}$, respectively. Moreover peak strengths $\left(\mathrm{f}_{\text {peak }}\right)$, average values and standard deviations (in parentheses) are reported in Table 2 . The dynamic tests performed are characterized by plate velocities equal to about $5 \mathrm{~m} / \mathrm{s}$, and this has produced average nominal strain-rates of $25 \mathrm{~s}^{-1}$ and $12.5 \mathrm{~s}^{-1}$ for the $200 \mathrm{~mm}$ and $400 \mathrm{~mm}$ specimens, respectively.

The results of the static tests, performed at the Politecnico di Milano, have been reported in the first colum of Table 3, where it is seen that standard concrete has a higher strength than dam one. Unfortunately, due to testing constraints, the longer specimens for static testing have been $300 \mathrm{~mm}$ long. As observed in Table 2, this is also true for the dynamic regime, where the standard concrete has a higher peak strength than the dam one for all specimen sizes investigated. Considering dam or standard concrete it is possible to highlight that the average peak strengths do not change significantly by increasing the specimen length from 200 to $400 \mathrm{~mm}$, whereas the standard deviation decreases when passing from 200 to $400 \mathrm{~mm}$ length for both materials. This decrease of standard deviation could suggest that specimens with $400 \mathrm{~mm}$ length are more representative for the materials considered.

Table 2. Dynamic compression tests results: plates velocities equal to about $5 \mathrm{~m} / \mathrm{s}$.

\begin{tabular}{lccccccc}
\hline Sample & $\begin{array}{c}\mathrm{f}_{\text {peak }} \\
\mathrm{MPa}\end{array}$ & $\begin{array}{c}\mathrm{f}_{\text {peak }, a v} \\
\mathrm{MPa}(\mathrm{std})\end{array}$ & $\begin{array}{c}\mathrm{G}_{\text {peak }} \\
\mathrm{J} / \mathrm{dm}^{3}\end{array}$ & $\begin{array}{c}\mathrm{G}_{\text {peak,av }} \\
\mathrm{J} / \mathrm{dm}^{3}(\mathrm{std})\end{array}$ & $\begin{array}{c}\mathrm{G}_{\text {tot }} \\
\mathrm{J} \mathrm{dm}^{3}\end{array}$ & $\begin{array}{c}\mathrm{G}_{\text {tot,av }} \\
\mathrm{J} / \mathrm{dm}^{3}(\mathrm{std})\end{array}$ & $\begin{array}{c}\text { Age } \\
{[\mathrm{dd}]}\end{array}$ \\
\hline DAM200 1 & 25.00 & & 235.97 & & 790.76 & & 324 \\
DAM200 2 & 26.70 & 27.23 & 277.99 & 322.93 & 845.93 & 784.91 & 332 \\
DAM200 3 & 30.00 & $(2.54)$ & 454.83 & $(116.15)$ & 718.04 & $(64.15)$ & 338 \\
DAM400 1 & 26.40 & & 109.90 & & 376.42 & & 331 \\
DAM400 2 & 26.80 & 27.20 & 93.25 & 104.97 & 369.79 & 374.59 & 345 \\
DAM400 3 & 28.40 & $(1.06)$ & 111.77 & $(10.19)$ & 377.57 & $(4.20)$ & 349 \\
STD200 1 & 33.90 & & 443.03 & & 481.30 & & 311 \\
STD200 2 & 30.60 & 31.97 & 284.12 & 410.54 & 664.72 & 570.69 & 338 \\
STD200 3 & 34.60 & $(3.97)$ & 504.47 & $(113.71)$ & 566.03 & $(91.80)$ & 344 \\
STD400 1 & 31.60 & & 201.32 & & 407.45 & & 350 \\
STD400 2 & 30.60 & 30.90 & 142.06 & 169.84 & 332.53 & 371.01 & 351 \\
STD400 3 & 30.50 & $(0.61)$ & 166.14 & $(29.81)$ & 373.06 & $(37.50)$ & 356 \\
\hline
\end{tabular}
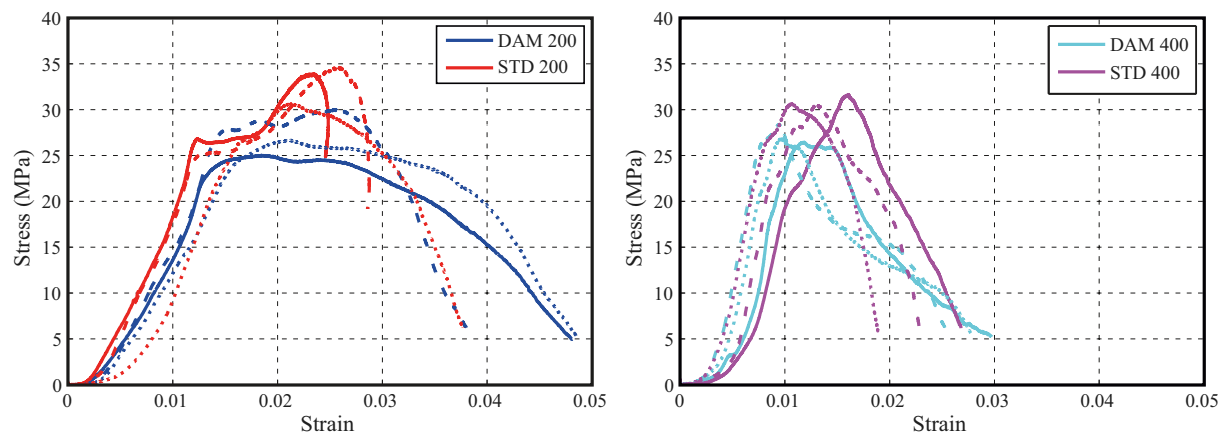

Fig. 4. Dynamic stress-strain trend of dam and standard concrete for different sample sizes: $200 \mathrm{~mm}$ (left) and $400 \mathrm{~mm}$ (right) length. 
Table 3 also reports the dynamic increase factor (DIF), computed as the ratio between dynamic and static average compressive strength. As already noticed from Table 2, in dynamic tests results the standard concrete is characterized by a higher value of compressive strength with respect to the dam one. However, focusing on the DIF analysis a different strain rate sensitivity of the two materials can be highlighted. The dam concrete exhibits greater values of DIF for the two sizes studied in comparison with the standard concrete. These results, being in agreement with the general behavioural pattern where lower strength concretes exhibit stronger strain-rate sensitivity, render credibility and confidence to the testing technique applied for such large specimens. Moreover, the DIF observed for samples with $400 \mathrm{~mm}$ length is higher than that recorded for shorter samples for both materials, and this difference is more noticeable when dam concrete is considered. Comparing the trend of Dynamic Increase Factor (DIF) vs. strain rate proposed by the Model Code 2010 [27] with the data obtained from the reported experimental campaign (see Fig. 5) it is possible to note that the behaviour suggested by the Code, which is calibrated starting from "small" samples of standard concretes, underestimates the results obtained in the current study carried out on large samples for both standard and dam concrete.

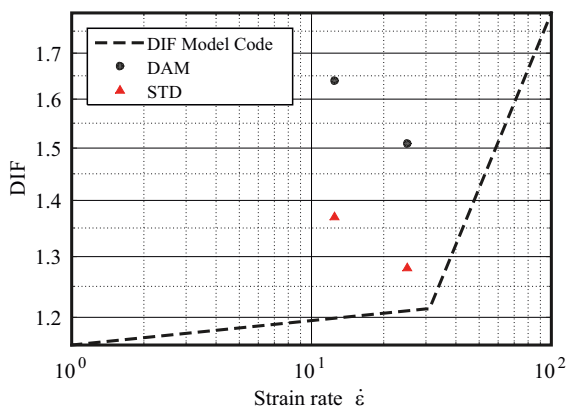

Fig. 5. DIF vs. strain rate.
Table 3. Static compressive strength and DIF.

\begin{tabular}{lcc}
\hline Sample type & $\begin{array}{c}\text { Static } \mathrm{f}_{\text {peak,av }} \\
\mathrm{MPa}(\mathrm{std})\end{array}$ & DIF \\
\hline DAM200 & $18.00(-)$ & 1.51 \\
DAM300 & $16.60(2.73)$ & 1.64 \\
STD200 & $22.60(2.43)$ & 1.28 \\
STD300 & $24.93(2.40)$ & 1.37 \\
\hline
\end{tabular}

On the basis of the above presented results, the energy $G$ absorbed during the dynamic tests (Table 2) has also been evaluated. $\mathrm{G}$ is computed as the area subtended by the stress-strain curve up to a specified strain $\bar{\varepsilon}$ (see Eq. (1)).

$$
G=\int_{0}^{\bar{\varepsilon}} \sigma(\varepsilon) d \varepsilon
$$

In Table 2 values of energy computed up to the peak strain $\left(\bar{\varepsilon}=\varepsilon_{\text {peak }}\right)$ and up to a value of strain corresponding to a stress equal to $20 \%$ of the peak one in the softening branch are reported. In Fig. 6 energy values and corresponding strain evaluation points are reported. Considering the energy involved in the fracture process up to the peak it is interesting to observe that standard concrete can absorb higher amounts of energy with respect to the dam concrete. The ratios between the computed energies $\left(G_{S T D} / G_{D A M}\right)$ are equal to 1.27 and 1.62 for the samples with a length equal to 200 and $400 \mathrm{~mm}$, respectively. The absorbed energy ratios change if total energies are considered, standard concrete samples with $200 \mathrm{~mm}$ length absorbed definitely less energy with respect to dam concrete samples $\left(G_{S T D} / G_{D A M}=0.72\right)$, while no appreciable difference appears for the samples with $400 \mathrm{~mm}$ length $\left(G_{S T D} / G_{D A M}=0.99\right)$. Considering the influence of specimen size on 

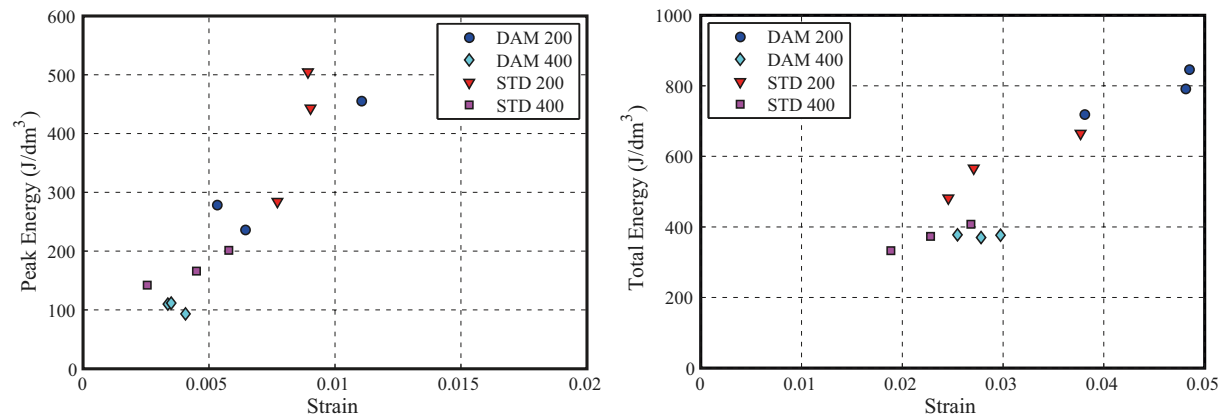

Fig. 6. Energy dissipated during test evaluated up to different limits: peak (a) and final (b) strain.

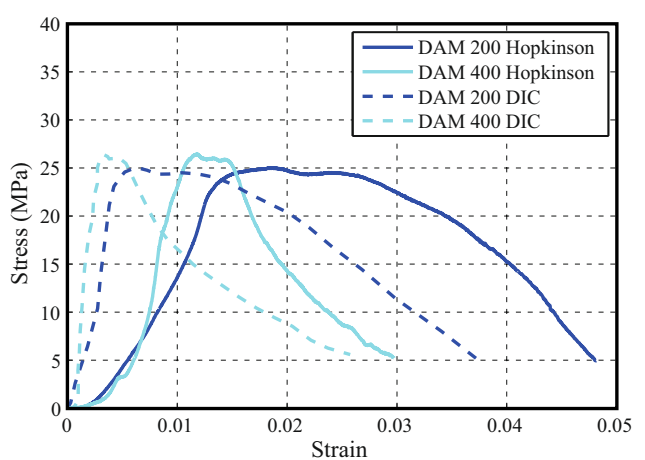

Fig. 7. Comparison between Hopkinson and DIC elaborations.

the energy absorbed during the fracturing process it is interesting to highlight that samples with $200 \mathrm{~mm}$ length can absorb more than twice the energy absorbed by samples with lengths of $400 \mathrm{~mm}$ for both the investigated materials, especially when peak energies are taken into account. In fact, the energy ratios $G_{200} / G_{400}$ are equal to 3.08 and 2.42 for dam and standard concrete, respectively. However these ratios decrease sensibly when total energies are considered. Attention is also drawn tho the fact that calculated values of energies cannot be considered directly in absolute terms because the strains obtained by applying Hopkinson bar theory (on the recorded signals from the bars) are overestimated (even if compensation and distortion are treated). This is mainly due to the fact that the apparatus, and in general the Split Hopkinson Pressure Bar testing, does not produce very accurate results in the small range of strain. However, the results can be sensibly improved exploiting the potentiality of DIC through local measures and especially by means of full-field measurements. By means of optical flow algorithms it has been possible to compute displacements and strains on the sample's visible surface. Thus by synchronizing and combining optical strain measurements with Hopkinson bar force measurements it is possible to improve the stress vs. strain curves obtained with the classical Hopkinson bar technique. Of course, the assumption of uniform stress and strain fields in the specimen is still imposed with this method. Figure 7 shows the comparison between the corresponding stress vs. strain curves obtained through Hopkinson bar and through combination of Hopkinson bar and optical techniques for dam concrete specimens with 200 and $400 \mathrm{~mm}$ length. The curves clearly demonstrate the improving effect of the applied 
optical strain correction, which renders the global material behaviour stiffer and moves the peak strength strain in the range of $0.2 \%-0.5 \%$, as expected.
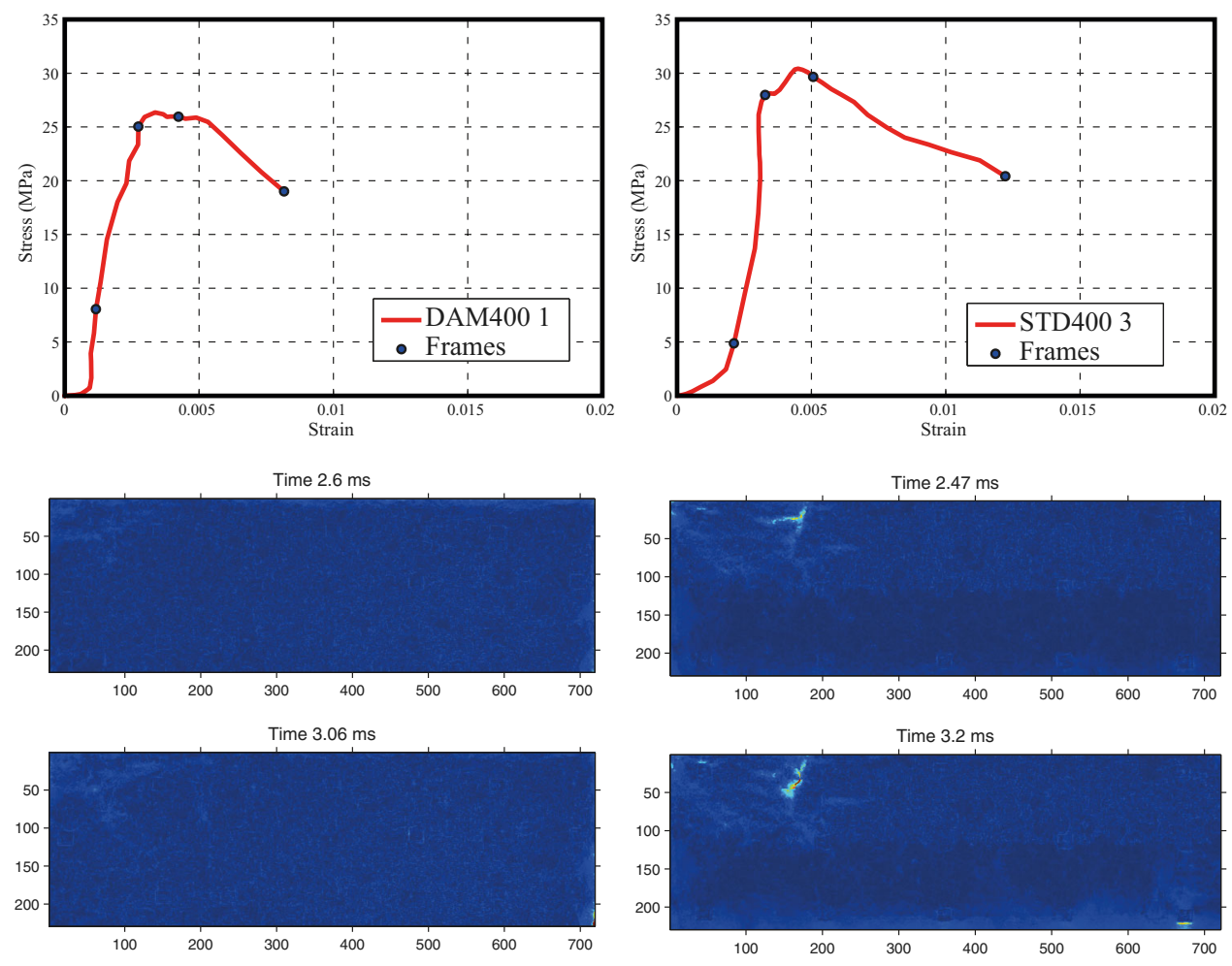

Time $3.46 \mathrm{~ms}$
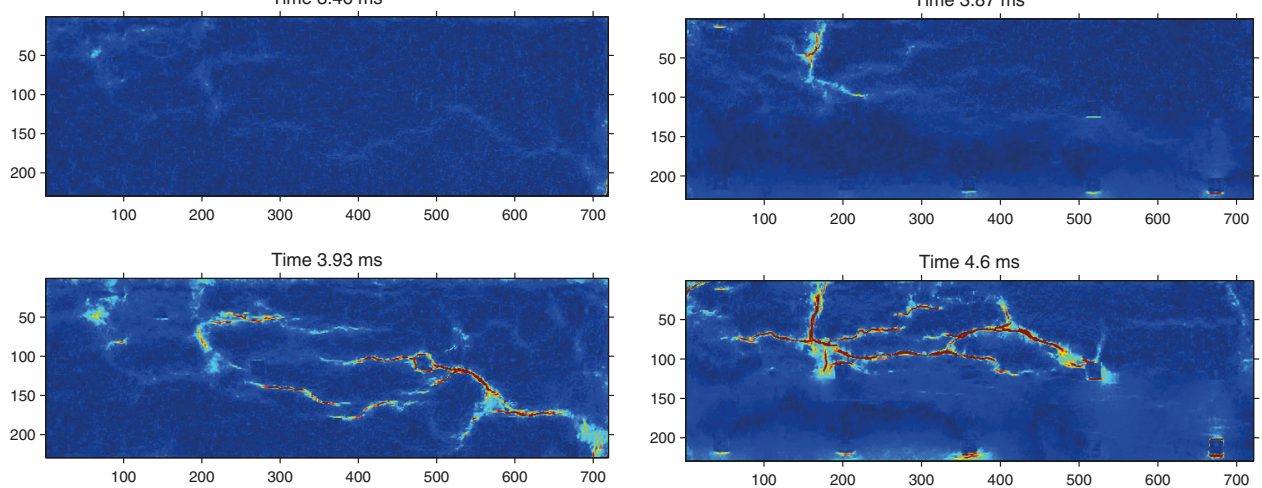

Fig. 8. Crack path evolution obtained trough Digital Image Correlation techniques: (a) dam concrete and (b) standard concrete sample.

As introduced above, full field optical techniques, like optical flow, can be used to evaluate in a qualitative and quantitative way the crack pattern development and distribution over the visible (monitored by the camera) cylindrical surface of the samples during the tests. In Fig. 8 an example of the crack pattern obtained by applying the optical flow algorithm at different time instants is shown for two samples of dam and standard concrete, with $400 \mathrm{~mm}$ length. The global stress and strain state 
of the specimen corresponding to each of these images is pointed out by the blue dots on the stress-strain curves.

\section{Conclusions}

A goal of the overall research project [20] was to advance the fundamental understanding and modeling capability of the complex and highly nonlinear response of dam concrete subject to extreme loading events, such as impacts and projectile penetration; in particular the influence of the aggregate size, the fracture energy etc., are desirable, since the modern constitutive laws for concrete are characterised by more parameters. An extensive and complete database of dam and standard concrete experimental data in both quasi-static and dynamic regime has been produced. This is a significant contribution since the current literature lacks such a complete set of data by which advanced numerical models can be calibrated and validated for the dam concretes [28]. This material is characterized by the presence of large aggregates, reducing the required content of cement per unit volume, and in this study the maximum aggregate diameter was chosen equal to $64 \mathrm{~mm}$. Large specimens have been considered in the experimental campaign in order to ensure a representative volume; cylindrical samples $200 \mathrm{~mm}$ diameter, and of 200 and $400 \mathrm{~mm}$ length were tested. An innovative modified Hopkinson bar facility designed for studying the response of large scale specimen under dynamic conditions, has been effectively utilised.

Analyzing the results in terms of compressive strength it was possible to highlight a higher strain rate sensitivity for the dam concrete with respect to the standard one. The DIF values observed in the test performed on samples with $400 \mathrm{~mm}$ length were higher with respect to those obtained for the smaller specimens, moreover this difference is accentuated for dam concrete. The energy involved in the dynamic fracturing process up to the peak strength of standard concrete was higher with respect to the dam concrete while the total energies were comparable. Samples of $200 \mathrm{~mm}$ length have exhibited a capacity to absorb energy two times higher than the longer ones. Combining DIC and Hopkinson bar analysis it was possible to improve the elaboration of the stress vs. strain curves of the materials investigated, moreover, by means of optical flow algorithms it was possible to follow the evolution of the crack pattern during the dynamic tests.

The financial support of part of this work under the DHS grant -2010-ST-108-000016 entitled High Strain Rate Behavior of Dam Concrete: Experiments and Multiscale Modeling is gratefully acknowledged.

\section{References}

1. C. Albertini, M. Montagnani, J. Phys. IV (France) 04, C8 (1994)

2. P. Bischoff, S. Perry, Mater. Struct. 24(6), 425 (1991)

3. D.L. Grote, S.W. Park, M. Zhou, Int. J. Impact Eng. 25(9), 869 (2001)

4. L.J. Malvar, C. Ross, ACI Materials J. 95(6), 735 (1998)

5. H. Schuler, C. Mayrhofer, K. Thoma, Int. J. Impact Eng. 32(10), 1635 (2006)

6. A. Zielinski, H. Reinhardt, Cement Concr. Res. 12(3), 309 (1982)

7. E. Cadoni, G. Solomos, C. Albertini, Mag. Concr. Res. 61(3), 221 (2009)

8. H.W. Reinhardt, J. Weerheijm, Int. J. Fract. 51, 31 (1991)

9. P. Rossi, J. van Mier, C. Boulay, F. Le Maou, Mater. Struct. 25, 509 (1992)

10. M. Curbach, J. Eibl, Eng. Fracture Mechs., Special Issue Fracture and Damage Concr. Rock 35, 321 (1990) 
11. R.M. Davies, Philosoph. Trans. Royal Society of London. Series A, Math. Phys. Sci. 240(821), 375 (1948)

12. B.A. Gama, S.L. Lopatnikov, J.W. Gillespie, Jr, Appl. Mech. Rev. 57(4), 223 (2004)

13. F. Jiang, K.S. Vecchio, Appl. Mech. Rev. 62(6), 060802 (2009)

14. T. Nicholas, Exper. Mech. 21(5), 177 (1981)

15. H. Reinhardt, H. Kormeling, A. Zielinski, Mater. Struct. 19(1), 55 (1986)

16. J. Weerheijm, J.A. Van Doormaal, Int. J. Impact Eng. 34(3), 609 (2007)

17. G. Staab, A. Gilat, Exper. Mech. 31, 232 (1991)

18. V. Saouma, J. Broz, E. Brühwiler, H. Boggs, J. Mater. Civil Eng. 3, 204 (1991)

19. P.H. Bischoff, S.H. Perry, H.J. Simon Engrg. Mech. 121, 685 (1995)

20. L. Cedolin, et al., High Strain Rate Behavior of Dam Concrete: Experiments and Multiscale Modeling (Final Report CONTRACT No. DHS-09-ST-108-001)

21. ACI Commitee 207, Guide to Mass Concrete (American Concrete Institute, USA 2006), p. 42

22. C.L. Bartholomew, M.L. Haverland, Concrete dam instrumentation manual (Interior Dept., Bureau of Reclamation, Denver, 1987), p. 165

23. M. Peroni, A. Caverzan, G. Solomos, Experimental Mechanics Online (2016)

24. M. Peroni, G. Solomos, B. Viaccoz, G. Magonette, R. Kiefer, EPJ Web of Conferences 26, 1 (2012)

25. H. Zhao, G. Gary, J. Mech. Phys. Solids 45, 1185 (1997)

26. A. Tyas, A.J. Watson, Int. J. Impact Eng. 25, 87 (2001)

27. A.A. V.V., Fib Bulletins 65-66, 720 (2012)

28. G. Cusatis, D. Pelessone, A. Mencarelli, Cement Concr. Compo. 33(9), 881 (2011)

Open Access This is an Open Access article distributed under the terms of the Creative Commons Attribution License (http://creativecommons.org/licenses/by/4.0), which permits unrestricted use, distribution, and reproduction in any medium, provided the original work is properly cited. 